\title{
Fractionated carbon ion irradiations of the rat spinal cord: comparison of the relative biological effectiveness with predictions of the local effect model
}

Maria Saager ${ }^{1,2,3}$, Christin Glowa $a^{1,2,3}$, Peter Peschke ${ }^{1,3}$, Stephan Brons ${ }^{4,3}$, Rebecca Grün ${ }^{5}$, Michael Scholz ${ }^{5}$, Jürgen Debus ${ }^{2,6,3}$ and Christian P. Karger ${ }^{1,3^{*}}$ (D)

\begin{abstract}
Background: To determine the relative biological effectiveness (RBE) and $\alpha / \beta$-values after fractionated carbon ion irradiations of the rat spinal cord with varying linear energy transfer (LET) to benchmark RBE-model calculations.

Material and methods: The rat spinal cord was irradiated with 6 fractions of carbon ions at 6 positions within a 6 cm spread-out Bragg-peak (SOBP, LET: 16-99 keV/ $\mu \mathrm{m}$ ). TD ${ }_{50}$-Values (dose at 50\% complication probability) were determined from dose-response curves for the endpoint radiation induced myelopathy (paresis grade II) within 300 days after irradiation. Based on $\mathrm{TD}_{50}$-values of $15 \mathrm{MV}$ photons, RBE-values were calculated and adding previously published data, the LET and fractional dose-dependence of the RBE was used to benchmark the local effect model (LEM I and IV).

Results: At six fractions, $\mathrm{TD}_{50}$-values decreased from $39.1 \pm 0.4 \mathrm{~Gy}$ at $16 \mathrm{keV} / \mu \mathrm{m}$ to $17.5 \pm 0.3 \mathrm{~Gy}$ at $99 \mathrm{keV} / \mu \mathrm{m}$ and the RBE increased accordingly from $1.46 \pm 0.05$ to $3.26 \pm 0.13$. Experimental $\alpha / \beta$-ratios ranged from $6.9 \pm 1.1 \mathrm{~Gy}$ to $44.3 \pm 7.2 \mathrm{~Gy}$ and increased strongly with LET. Including all available data, comparison with model-predictions revealed that (i) LEM IV agrees better in the SOBP, while LEM I fits better in the entrance region, (ii) LEM IV describes the slope of the RBE within the SOBP better than LEM I, and (iii) in contrast to the strong LETdependence, the RBE-deviations depend only weakly on fractionation within the measured range.

Conclusions: This study extends the available RBE data base to significantly lower fractional doses and performes detailed tests of the RBE-models LEM I and IV. In this comparison, LEM IV agrees better with the experimental data in the SOBP than LEM I. While this could support a model replacement in treatment planning, careful dosimetric analysis is required for the individual patient to evaluate potential clinical consequences.
\end{abstract}

Keywords: Carbon ion radiotherapy, Linear energy transfer (LET), Relative biological effectiveness (RBE), Dose response curves, Rat spinal cord, Local effect model (LEM)

\footnotetext{
* Correspondence: c.karger@dkfz.de

'Department of Medical Physics in Radiation Oncology, German Cancer

Research Center (DKFZ), Heidelberg, Germany

${ }^{3}$ National Center for Radiation Research in Oncology (NCRO), Heidelberg

Institute for Radiation Oncology (HIRO), Heidelberg, Germany

Full list of author information is available at the end of the article
}

(c) The Author(s). 2019 Open Access This article is distributed under the terms of the Creative Commons Attribution 4.0 International License (http://creativecommons.org/licenses/by/4.0/), which permits unrestricted use, distribution, and reproduction in any medium, provided you give appropriate credit to the original author(s) and the source, provide a link to the Creative Commons license, and indicate if changes were made. The Creative Commons Public Domain Dedication waiver (http://creativecommons.org/publicdomain/zero/1.0/) applies to the data made available in this article, unless otherwise stated. 


\section{Background}

Ion beams exhibit finite ranges in tissue and allow for highly conformal irradiation of tumors by using spreadout Bragg-peaks (SOBP) [1]. Carbon ions show a significantly higher biological effectiveness than protons [2] and clinical trials are ongoing to test whether this feature improves outcome in patients [3]. The increased effectiveness of ions is measured by the relative biological effectiveness (RBE) given as the ratio of photon and ion doses that lead to the same biological endpoint. The RBE of carbon ions is a complex quantity and depends strongly on linear energy transfer (LET), fractional dose as well as on biological factors like repair capacity and others [2].

Based on early experience at the Lawrence Berkley Laboratory (USA) [4], carbon ions have been introduced clinically in 1994 at the National Institute of Radiological Sciences (Japan) [5] followed by other institutions in Germany, Japan, Italy, China and Austria [3]. When treating patients, the RBE is calculated by models [6-8] and clinical results are critically affected by their accuracy [3]. Presently, the mixed beam model (MBM) [6], the local effect model (LEM) [7] and the microdosimetric kinetic model (MKM) [8] are employed in patients. While development and initial validation of these models was mainly based on in vitro data, less effort has been performed to validate them by preclinical in vivo studies, mainly because of the limited availability of in vivo RBEs, especially for late effects.

In previous studies $[9,10]$, the RBE of carbon ions was determined in the rat spinal cord, which has been established as a model for late normal tissue effects [11]. These measurements were performed only in the entrance region of a mono-energetic Bragg-peak and at the center of a $1 \mathrm{~cm}$ SOBP and allowed for initial benchmarking of the clinically applied version of the local effect model (LEM I) at very low and high LETs. Deviations found in this comparison lead to the development of the newer version LEM IV [12], however, LEM I is still used clinically up to now and it remains to be shown, whether LEM I or LEM
IV describes the RBE more accurately, as detailed information on the LET- and dose-dependence is lacking.

More recently, a large series of experiments investigated the RBE of carbon ions in the rat spinal cord after single and split doses at 6 positions within a $6 \mathrm{~cm} \mathrm{SOBP}$ [13-15]. The present study extends these experiments to 6 fractions allowing for the analysis of the RBEdependence on LET at significantly lower fractional doses as well as the dose-dependence of the RBE. These data are employed to systematically test the RBEcalculation by the RBE-models LEM I and IV.

\section{Methods \\ Animals}

This study was performed with 209 young adult female Sprague Dawley rats $(208 \pm 12$ g, Charles River, Sulzfeld, Germany). Animals were irradiated under inhalation anesthesia with a mixture of $4 \%$ Sevoflurane (Abbott, Wiesbaden, Germany) and 21/min oxygen using a $50 \mathrm{ml}$ disposable syringe as a mask. Experiments were approved by the governmental review committee on animal care (35-9185.81/G62-08, G117/13), and animals were kept under standard conditions at the DKFZ Center for Preclinical Research.

\section{Experimental setup}

The experimental setup was the same as in previous studies [13-15]. The spinal cord was positioned at 6 different depths of a $6 \mathrm{~cm}$ SOBP (70 to $130 \mathrm{~mm}$ water-equivalent depth, $187-260 \mathrm{MeV} / \mathrm{u}$ ), which was optimized to a uniform absorbed dose in the Bragg-peak region using the treatment planning system TRiP (treatment planning for particles) [16]. The different depths correspond to different dose-averaged LET-values (Table 1) and accordingly to different RBE-values. The field size was $10 \times 15 \mathrm{~mm}^{2}$ and included the cervical segments C1-C6 [13-15]. The depth of the spinal cord in the SOBP was adjusted with polymethyl-methacrylate (PMMA)-boli.

Table 1 Dose levels and animal numbers used for the experiments

\begin{tabular}{llll}
\hline Water-equivalent depth $[\mathrm{mm}]$ & LET $[\mathrm{keV} / \mu \mathrm{m}]$ & Dose levels [Gy] & Total number of animals \\
\hline 35 & 16 & $37^{c}, 38,39,40,41,45,49^{b}$ & 37 \\
65 & 21 & $30,32,34,36,38,40$ & 30 \\
80 & 36 & $25.5,28.5^{\mathrm{d}}, 31.5,34.5$ & 20 \\
$100^{\mathrm{a}}$ & 45 & $21.67,24.49,26.38,28.26,30.14,32.97$ & 30 \\
120 & 66 & $14.5,15.5,16.5^{f}, 17.5^{e}, 18.5,19.5,20.5,21.5,22.5,23.5,24.5$ & 55 \\
127 & 99 & $15,16,17,18^{e}, 19,20$ & 32 \\
& & controls & 5
\end{tabular}

\footnotetext{
axperiment was performed at GSI, Darmstadt

${ }^{b}$ One animal died due to unknown reasons

${ }^{\mathrm{C}}$ Two animals died during irradiation narcosis

${ }^{\mathrm{d}}$ One animal died during irradiation narcosis

'One animal had to be excluded due to the development of mammary carcinomas (199 d and $200 d$, respectively)

${ }^{f}$ Two animals had to be excluded due to the development of mammary carcinomas (158 $d$ and $257 d$, respectively)
} 
At each depth, the spinal cord was irradiated with 6 daily fractions $(\mathrm{Fx})$ of carbon ions. Animals were irradiated with different dose levels in groups of five animals (Table 1), both selected to obtain similar statistical accuracy as in previous experiments [13-15]. Doses covered $0-100 \%$ response probability and five animals were included as sham treated controls. The mid-SOBP position was irradiated at the Helmholtz Center for Heavy Ion Research (GSI), all other experiments were performed under identical conditions at the Heidelberg Ion-Beam Therapy Center (HIT). In all experiments the active raster scanning method was employed [17]. Prescribed doses refer to the maximum dose measured with a pinpoint ionization chamber (TM31009, PTW Freiburg, Germany).

\section{Follow-up and biological endpoint}

After irradiation, rats were monitored weekly for weight and general condition. The biological endpoint was radiation induced myelopathy (paresis grade II) within 300 days, meaning that both forelimbs show signs of paralysis [9]. Rats exhibiting this endpoint were sacrificed and scored as responder.

\section{Data analysis}

Data analysis was performed as in previous studies [9, 10, 13-15]. For each SOBP-depth, a dose-response curve and the dose at $50 \%$ complication probability, $\mathrm{TD}_{50}$, was determined (Appendix 1). Using the previously measured dose-response curve for $15 \mathrm{MeV}$ photons [10], the $\mathrm{RBE}$ was calculated as the ratio of the $\mathrm{TD}_{50}$-values for photons and carbon ions. Including additionally data for 1 and 2 fractions [13-15], the fractionation parameter $\alpha / \beta$ and the biologically effective dose at $50 \%$ complication probability, $B E D_{50}$, of the linear-quadratic (LQ) model [18] were calculated for all SOBP-depths (Appendix 2). Using previously determined $B E D_{50}$-values for photon irradiations $[9,10]$, the maximum RBE in the limit of low doses was estimated as the ratio of the $B E D_{50}$-values of photons and carbon ions.

\section{RBE calculations}

The RBE-values were calculated at the 6 depths of the spinal cord within the SOBP using the clinically applied LEM I [7] as well as the newer version LEM IV [12], employing the so-called 'full-simulation' approach [19]. The RBE was calculated at the $\mathrm{TD}_{50}$-dose levels obtained for carbon ions using the standard parameters for LEM I $\left(\alpha / \beta=2 G y, \alpha=0.1 G y^{-1}, D_{t}=30 G y\right)$ and LEM IV $\left(\alpha / \beta=2 G y, \alpha=0.003 G y^{-1}, D_{t}=22 G y\right)$ [20]. Maximum RBE-values were calculated from the ratio of $\alpha$-values of carbon ions photons.

\section{Statistics}

Dose-response curves were adjusted using the maximum likelihood procedure of STATISTICA [21]. Incomplete follow-up of animals was considered using the method of effective sample sizes [22] that corrects the number of treated and responding animals to match actuarial response rates and their variances. Standard errors (SE) of $\mathrm{TD}_{50}, \mathrm{RBE}$ and $\alpha / \beta$ were calculated by error propagation considering the correlation of the underlying parameters and Fieller's Theorem [23] was used to calculate 90\% confidence limits (CL). If the SE could not be calculated by STATISTICA, it was estimated as $25 \%$ of the dose difference between the neighbouring 0 and 100\% doseresponse levels [13].

\section{Results}

Irradiation was well tolerated by the animals. Four out of 209 animals died for unknown reasons and four animals had to be excluded due to the development of mammary carcinomas (Table 1). Acute toxicity developed within 3 weeks after treatment including a slight or complete transient hair loss and moist desquamation of the skin. Mean and minimum latency time of radiation induced myelopathy decreased slightly with increasing LET, fraction number and dose (Figs. 1 and 2).

With increasing LET, the dose-response curves were shifted to lower doses (Figs. 3 and 4). This is expressed quantitatively by the $\mathrm{TD}_{50}$-values (Table $2 \mathrm{~A}$ ) and as a result, the RBE increased with LET. Table $2 \mathrm{~B}$ displays the $\mathrm{BED}_{50}$-values and the corresponding maximum RBEvalues representing the expected upper limits for very small fractional doses.

Including previous photon data, Fig. 5 displays the dependence of the RBE and the extrapolated maximum RBE on LET, depth and fractional dose in comparison to

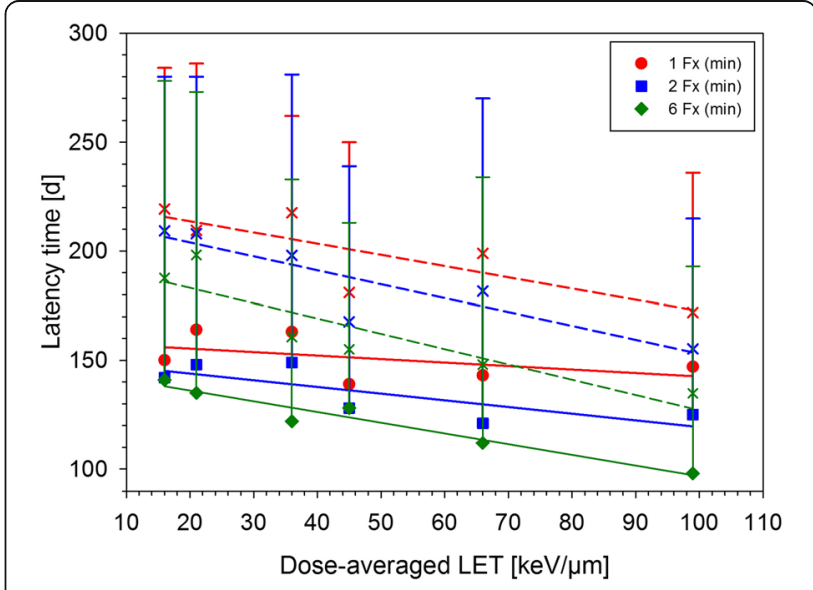

Fig. 1 Minimum (closed symbols, solid line) and mean (crosses, dashed line) latency times for the onset of paresis grade II after carbon ion irradiation as a function of LET including data for single and split doses [13-15]. Error bars indicate the range of latency times 

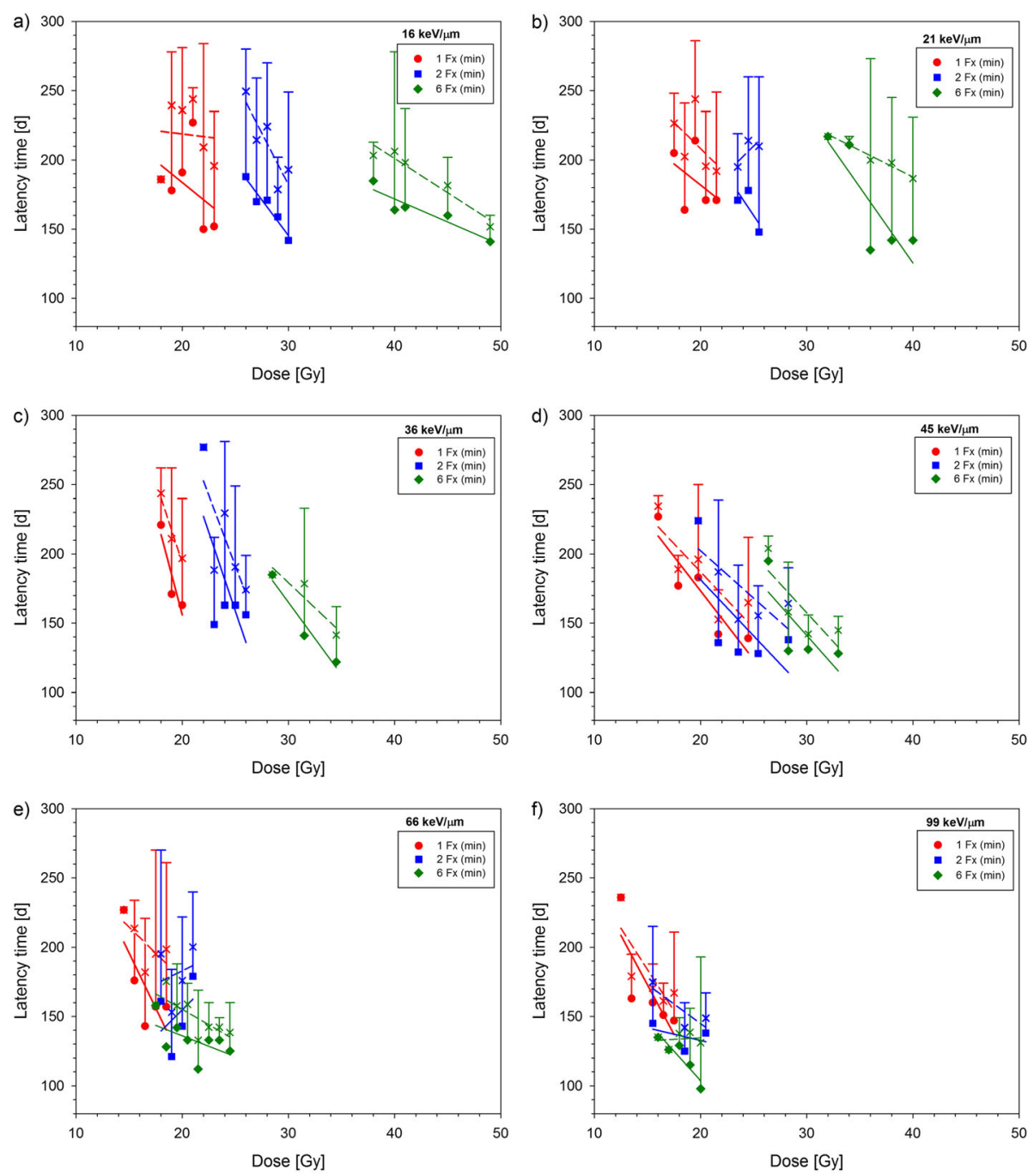

Fig. 2 Minimum (closed symbols, solid lines) and mean (crosses, dashed lines) latency times for the onset of paresis grade II after carbon ion irradiation as a function of dose for different LETs (a-f). Data for single and split doses was obtained in previous studies [13-15]. Error bars indicate the range of latency times

the model predictions. Table 3 summarizes the average deviations between measured and predicted values numerically.

While LEM I describes the RBE best at $16 \mathrm{keV} / \mu \mathrm{m}$ and deviates increasingly towards higher LETs, LEM IV fits best at $99 \mathrm{keV} / \mu \mathrm{m}$ and deviates increasingly at intermediate and low LETs (Fig. 5a). Quantitatively, LEM I differs by $-20.1 \%(-19.9--20.7)$ in the SOBP while LEM IV deviates only $-8.3 \%$, $(-6.6--11.3 \%)$ (Table $3 \mathrm{~A})$. In contrast, the deviations in the entrance region are larger for LEM IV $(-21.5,-17.8 \%--26.9 \%)$ than for LEM I (- 7.2, $-3.0 \%--11.2 \%)$ and LEM IV generally underestimates the RBE at low LETs (Table 3B). Only the extrapolated $\mathrm{RBE}_{\max }$-values show similar mean deviations in the SOBP for LEM I and IV (-1.7\% vs 4.8\%), however they deviate increasingly but in opposite directions at low and high
LETs, respectively (Fig. 5b). As compared to measurements, the slope of the LET-dependent RBE within the SOBP region was significantly more shallow for LEM I (ratio: 0.44, 0.37-0.51) and somewhat steeper for LEM IV (ratio 1.21, 1.17-1.27) (Table 3C) corresponding to a more pronounced increase of the RBE with depth (Fig. 5c,d). Finally, the experimental RBE of the single and split dose studies exhibit an essentially linear increase with LET, while the fits to the 6 fraction experiment as well as to the extrapolated maximum RBE start to saturate between 66 and $99 \mathrm{keV} / \mu \mathrm{m}$.

Comparing the dose-dependence, LEM IV reproduces almost exactly the measured RBE-curve at $99 \mathrm{keV} / \mu \mathrm{m}$ while LEM I markedly underestimates the RBE over the whole dose range (Fig. $5 \mathrm{e}, \mathrm{f}$ ). At $16 \mathrm{keV} / \mu \mathrm{m}$, however, the consistently increased experimental RBE of $1.3-1.5$, is not described 

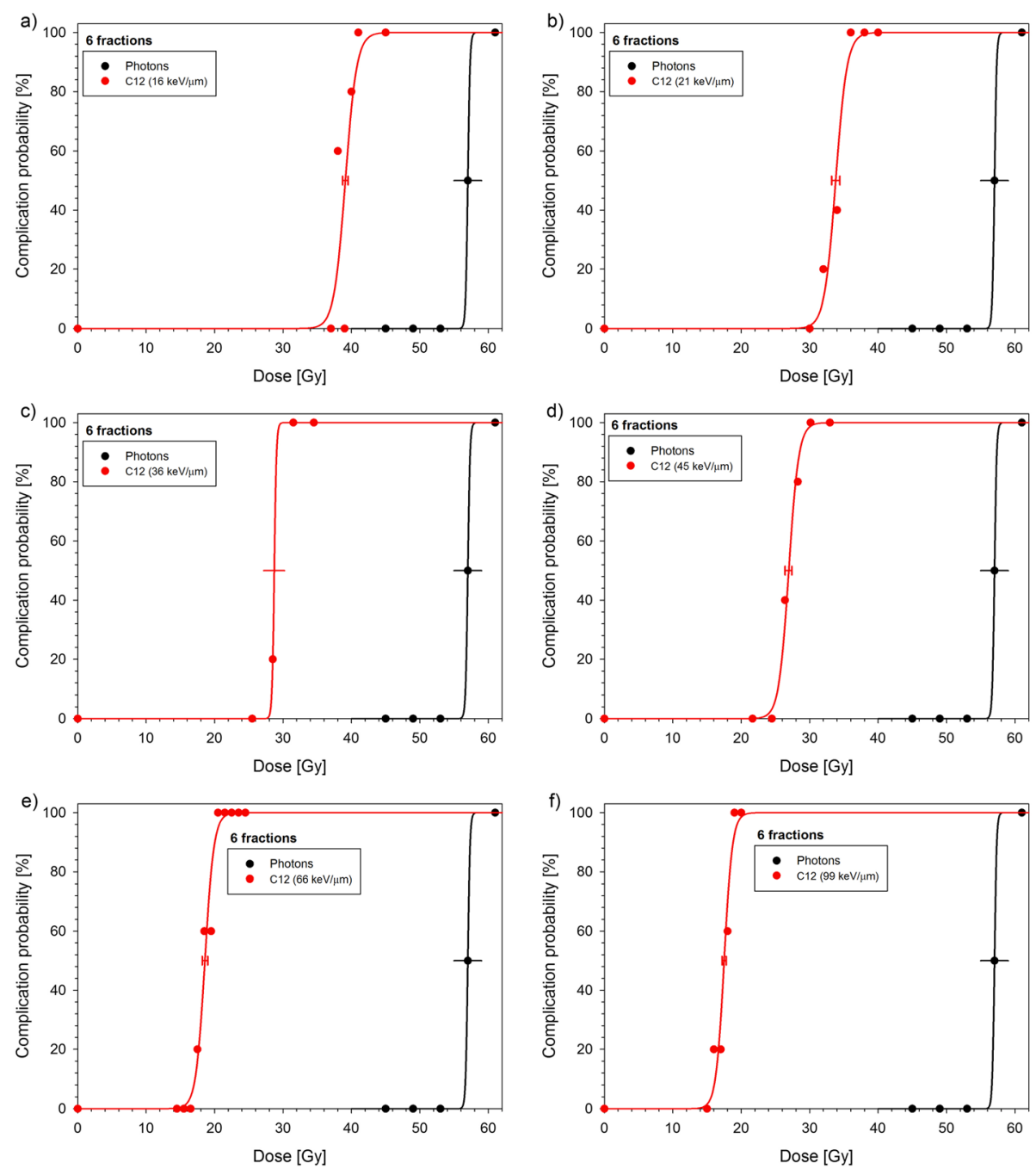

Fig. 3 Dose-response curves after 6 Fx of carbon ions measured at different SOBP-depths (a-f) together with the previously published photon curve [10]. Error bars indicate $1 \mathrm{SE}$ of $\mathrm{TD}_{50}$. Error bars with caps are based on the fit while those without were estimated (see text)

by LEM IV. This increase is better described by LEM I although the slope of the RBE with dose is larger than for the measured data. Generally, the deviations of measured and calculated RBE varied only weakly (SD of $1-6 \%$ ) between the different fractionation schedules (Table 3D).

Performing a linear regression to the experimentally obtained $\alpha / \beta$-ratios revealed strong increase with LET (Fig. 6 and Table 2C). This is reflected by both LEM versions, however, with a systematically higher value for LEM I than for LEM IV.

\section{Discussion}

\section{Methods for validating RBE-models}

Clinically, the RBE-concept pursues two aims: (i) weighting the absorbed dose distribution according to the local beam quality to achieve a uniform biological effect in the SOBP, and (ii) prescribing an RBE-weighted dose being approximatively equivalent to a photon treatment. As the RBE impacts the treatment effectiveness, RBEmodels require tests of increasing clinical relevance.

Initially, RBE-models were developed based on cell experiments using clonogenic survival as endpoint, thereby neglecting interactions between cells or impact of physiological and micro-environmental factors. However, especially late effects do not solely result from inactivation of cell populations $[24,25]$ and it is therefore important to benchmark RBE-models additionally in vivo. For this, the rat spinal cord is an established model [9-11, 26, 27] providing a well-detectable endpoint and a volumeindependent response, if the irradiated segment is larger than $8 \mathrm{~mm}$ [28]. Hence, our study measures the RBE for the local radiation quality related to the only marginal LET-variation within the cross-section of the rat spinal 


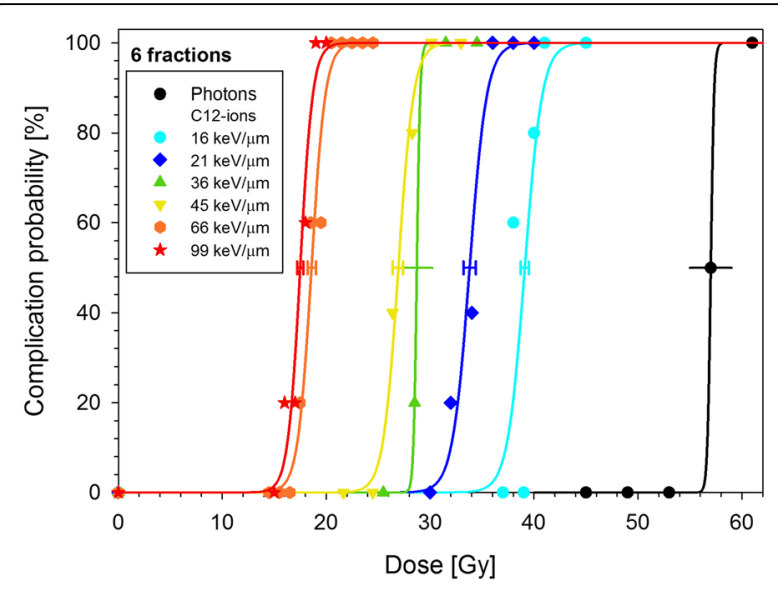

Fig. 4 Summarized dose-response curves after 6 fractions of carbon ions as a function of LET together with the previously measured photon curve [10]. Error bars indicate $1 \mathrm{SE}$ of $\mathrm{TD}_{50}$. Error bars with caps are based on the fit while those without were estimated (see text)

cord. This is considered as the consequent next step after measuring the RBE locally for isolated cells.

We recall that the models used here predict local RBEvalues at each point in the tissue and do not consider volume effects as they occur in organs of the central nervous system like e.g. the brain, where smaller irradiated volumes increase radiation tolerance and thereby reduce the risk of side effects. Disregarding the volume-effect, the rat spinal cord therefore is a particularly suitable in vivo system to benchmark the LET- and dose-dependence of RBE-models. Further developments of models and advanced experimental approaches as reported in [29] would be required to reliably disentangle high-LET-, dose- and volume-effects.

\section{Benchmarking LEM I and IV}

The present study extends the available RBE data base to significantly lower fractional doses. Altogether, the data provides a comprehensive and consistent set of RBE-values for carbon ions as a function of LET at different dose levels. These data were used to benchmark predictions of the LEM (Fig. 5). Based on these comparisons, we conclude that (i) LEM IV agrees better in the SOBP, while LEM I fits better in the entrance region, (ii) LEM IV describes the slope of the RBE within the SOBP better than LEM I, and (iii) in contrast to the strong LET-dependence, the RBE-deviations depend only weakly on fractionation within the measured range.

Interestingly, while the RBE increased linearly with LET for single and split doses, the $6 \mathrm{Fx}$ experiment as well as the extrapolated maximum RBE exhibited a slight saturation. This could be a first indication of the so-called overkill-effect, well-known from cell experiments which leads to a decreased RBE beyond $150-200 \mathrm{keV} / \mu \mathrm{m}$ [30].

Finally, the interpolated $\alpha / \beta$-values rise with LET consistently with the increasingly linear cell survival curves
Table 2 Determined values for $\mathrm{TD}_{50}, \mathrm{BED}_{50}, \mathrm{RBE}, \mathrm{RB} E_{\max }$ and $\mathrm{a} / \mathrm{\beta}$ together with the single standard errors (SE) and 90\%-confidence limits (CL)

\begin{tabular}{|c|c|c|}
\hline Study & $\mathrm{TD}_{50} \pm \mathrm{SE}(90 \% \mathrm{CL})[\mathrm{Gy}]$ & $\mathrm{RBE} \pm \mathrm{SE}(90 \% \mathrm{CL})$ \\
\hline \multicolumn{3}{|l|}{ (A) $6 \mathrm{Fx}$} \\
\hline Photons ${ }^{a}$ & $57.0 \pm 2.0(-)^{b}$ & \\
\hline \multicolumn{3}{|l|}{ Carbon ions } \\
\hline $16 \mathrm{keV} / \mu \mathrm{m}$ & $39.1 \pm 0.4(38.2-40.0)$ & $1.46 \pm 0.05(1.37-1.55)$ \\
\hline $21 \mathrm{keV} / \mu \mathrm{m}$ & $33.8 \pm 0.6(32.5-35.0)$ & $1.69 \pm 0.07(1.58-1.80)$ \\
\hline $36 \mathrm{keV} / \mu \mathrm{m}$ & $28.7 \pm 1.5(-)^{b}$ & $1.98 \pm 0.12(1.79-2.21)$ \\
\hline $45 \mathrm{keV} / \mu \mathrm{m}$ & $26.9 \pm 0.5(25.7-28.1)$ & $2.12 \pm 0.08(1.98-2.26)$ \\
\hline $66 \mathrm{keV} / \mu \mathrm{m}$ & $18.6 \pm 0.4(17.8-19.3)$ & $3.07 \pm 0.12(2.87-3.27)$ \\
\hline $99 \mathrm{keV} / \mu \mathrm{m}$ & $17.5 \pm 0.3(16.8-18.2)$ & $3.26 \pm 0.13(3.05-3.48)$ \\
\hline (B) 1,2 and $6 \mathrm{Fx}$ & $\mathrm{BED}_{50} \pm \mathrm{SE}(90 \% \mathrm{CL})[\mathrm{Gy}]$ & $\mathrm{RBE}_{\max } \pm \mathrm{SE}(90 \% \mathrm{CL})$ \\
\hline Photons ${ }^{a}$ & $244.9 \pm 24.3(208.2-293.3)$ & \\
\hline \multicolumn{3}{|l|}{ Carbon ions } \\
\hline $16 \mathrm{keV} / \mu \mathrm{m}$ & $76.3 \pm 7.2(66.0-92.0)$ & $3.21 \pm 0.44(2.55-4.02)$ \\
\hline $21 \mathrm{keV} / \mu \mathrm{m}$ & $53.3 \pm 3.7(47.7-60.9)$ & $4.59 \pm 0.55(3.73-5.57)$ \\
\hline $36 \mathrm{keV} / \mu \mathrm{m}$ & $39.5 \pm 2.3(36.0-44.6)$ & $6.21 \pm 0.71(5.09-7.44)$ \\
\hline $45 \mathrm{keV} / \mu \mathrm{m}$ & $36.4 \pm 1.8(33.2-40.3)$ & $6.73 \pm 0.74(5.55-8.00)$ \\
\hline $66 \mathrm{keV} / \mu \mathrm{m}$ & $20.3 \pm 0.6(19.4-21.3)$ & $12.07 \pm 1.24(10.05-14.13)$ \\
\hline $99 \mathrm{keV} / \mu \mathrm{m}$ & $19.0 \pm 0.6(18.1-20.1)$ & $12.87 \pm 1.33(10.71-15.08)$ \\
\hline (C) 1,2 and $6 \mathrm{Fx}$ & $\alpha / \beta \pm S E(90 \% C L)[G y]$ & \\
\hline Photons ${ }^{a}$ & $2.8 \pm 0.4(2.2-3.5)$ & \\
\hline \multicolumn{3}{|l|}{ Carbon ions } \\
\hline $16 \mathrm{keV} / \mu \mathrm{m}$ & $6.9 \pm 1.1(5.2-8.9)$ & \\
\hline $21 \mathrm{keV} / \mu \mathrm{m}$ & $9.8 \pm 1.3(7.7-12.2)$ & \\
\hline $36 \mathrm{keV} / \mu \mathrm{m}$ & $14.6 \pm 1.9(11.4-18.2)$ & \\
\hline $45 \mathrm{keV} / \mu \mathrm{m}$ & $12.8 \pm 1.5(10.3-16.4)$ & \\
\hline $66 \mathrm{keV} / \mu \mathrm{m}$ & $44.3 \pm 7.2(33.8-60.4)$ & \\
\hline $99 \mathrm{keV} / \mu \mathrm{m}$ & $30.8 \pm 4.6(23.9-40.9)$ & \\
\hline
\end{tabular}

${ }^{a}$ Data obtained or derived from [10]

${ }^{\boldsymbol{b}}$ Estimated standard error, confidence limits could not be determined (see text)

for carbon ions. This confirms a reduced repair capacity and in spite of systematic differences between LEM I and IV, both LEM-versions describe the $\alpha / \beta$-values reasonably well when considering experimental uncertainties.

\section{Clinical handling of RBE-models}

Our measurements indicated that LEM IV is more accurate in the SOBP at least up to 6 fractions. Although this might suggest a replacement of LEM I in treatment planning, additional aspects need to be considered: While the RBE-weighted dose distributions optimized with both models will look very similar, the underlying RBEs will differ, leading to different absorbed doses and thus effectiveness in tumor and normal tissues. 

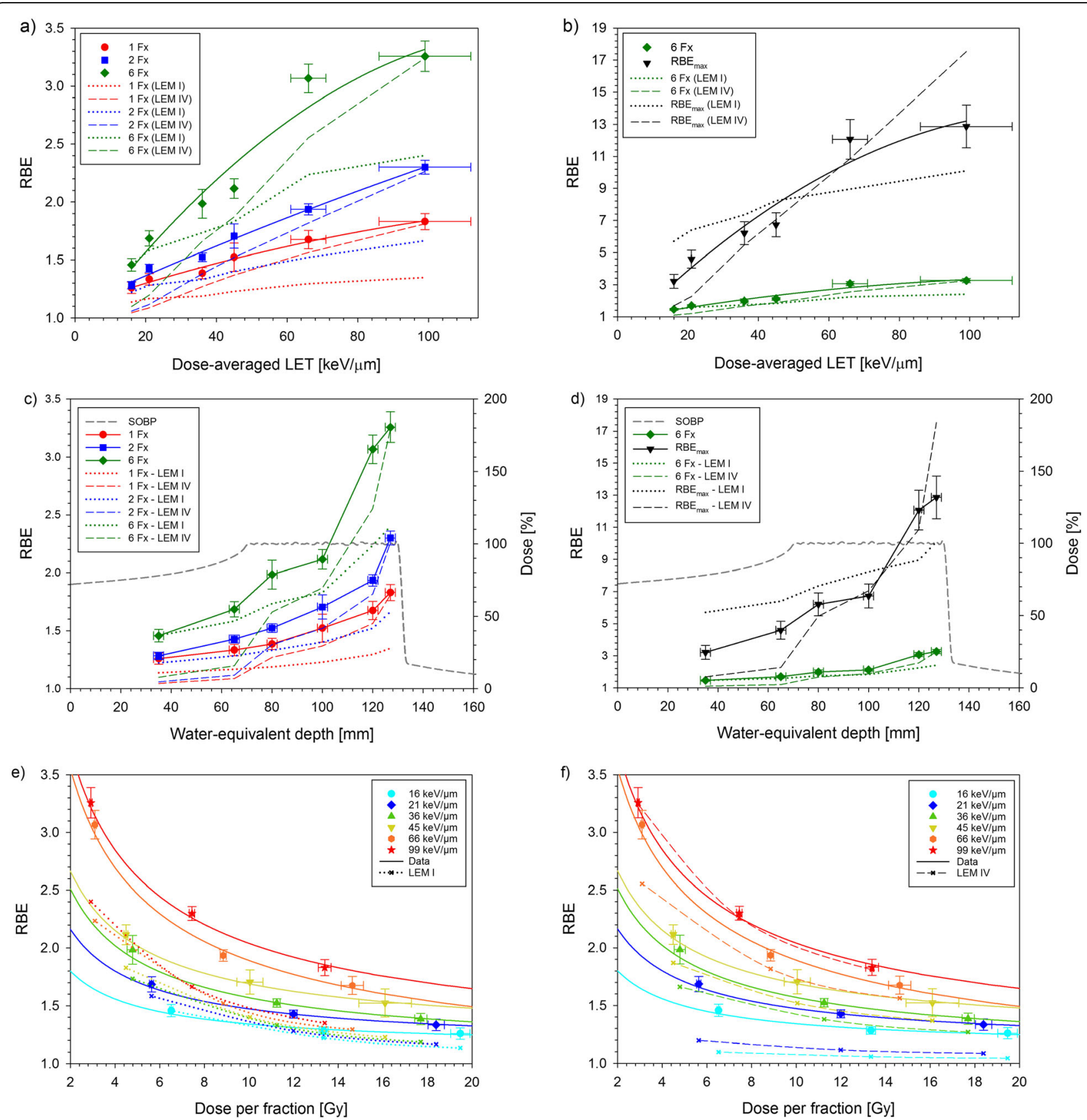

Fig. 5 RBE as a function of LET $(\mathbf{a}, \mathbf{b})$, depth $(\mathbf{c}, \mathbf{d})$ and fractional dose $(\mathbf{e}, \mathbf{f})$ including previous data for single and split doses [13-15]. For the experimental data, the LET-dependence was fitted by $2^{\text {nd }}$ order polynomials while the dose-dependence was inter- and extrapolated with the LQ-model using the experimentally obtained $a / \beta$-ratios

Furthermore, although the clinically applied LEM I underestimated the RBE in the rat spinal cord at high LETs, this may have been compensated in patients by prescribing a lower dose as the prescribed dose represents an independent treatment parameter. This raises the question, whether RBE-models should actually predict the absolute RBE or only its relative LET- and dose-dependence. The latter approach is followed at the Japanese centers $[6,8]$, where in vitro RBE-depth profiles are normalized to the clinical RBE. Moreover, the clinical RBE is not changed with fractionation and the altered effectiveness was rather considered by changing the prescribed dose $[2,3]$. Thus, after successful dose finding, the remaining question is, whether a more accurate relative RBE-distribution would improve treatment outcome.

With respect to the RBE-profile, it has to be noted that the target volume contains mostly tumor rather than 
Table 3 Average deviations of LEM-predictions from experimental data. Values are given as mean \pm 1 SD (A, B, D) or \pm 1 SE (C), respectively

\begin{tabular}{|c|c|c|}
\hline & LEM I & LEM IV \\
\hline (A) Fx & RBE-deviation averaged over SOBP region ${ }^{c}[\%]$ & \\
\hline 1 & $-20.7 \pm 5.1$ & $-6.6 \pm 3.9$ \\
\hline 2 & $-19.9 \pm 6.3$ & $-7.0 \pm 4.1$ \\
\hline 6 & $-19.9 \pm 7.9$ & $-11.3 \pm 7.6$ \\
\hline$\infty(\text { limit } d \rightarrow 0)^{a}$ & $-1.7 \pm 25.5$ & $4.8 \pm 22.3$ \\
\hline (B) Fx & RBE-deviation averaged over entrance region ${ }^{\mathrm{b}}[\%]$ & \\
\hline 1 & $-11.2 \pm 1.9$ & $-17.8 \pm 1.0$ \\
\hline 2 & $-7.5 \pm 3.8$ & $-19.7 \pm 3.0$ \\
\hline 6 & $-3.0 \pm 4.3$ & $-26.9 \pm 3.1$ \\
\hline$\infty(\text { limit } d \rightarrow 0)^{a}$ & $58.6 \pm 27.2$ & $-49.2 \pm 2.2$ \\
\hline (C) Fx & Slope ratio in SOBP region ${ }^{c}$ & \\
\hline 1 & $0.37 \pm 0.08$ & $1.27 \pm 0.21$ \\
\hline 2 & $0.44 \pm 0.04$ & $1.17 \pm 0.08$ \\
\hline 6 & $0.51 \pm 0.18$ & $1.19 \pm 0.35$ \\
\hline$\infty(\text { limit } d \rightarrow 0)^{a}$ & $0.36 \pm 0.12$ & $1.68 \pm 0.53$ \\
\hline (D) LET [keV/um] & RBE-deviation averaged over 1, 2 and 6 fractions [\%] & \\
\hline 16 & $-4.9 \pm 4.9$ & $-19.8 \pm 4.3$ \\
\hline 21 & $-9.6 \pm 3.3$ & $-23.1 \pm 5.4$ \\
\hline 36 & $-13.2 \pm 1.0$ & $-11.4 \pm 4.3$ \\
\hline 45 & $-16.9 \pm 3.0$ & $-10.9 \pm 0.7$ \\
\hline 66 & $-23.7 \pm 3.0$ & $-9.8 \pm 6.0$ \\
\hline 99 & $-26.7 \pm 0.8$ & $-1.1 \pm 0.6$ \\
\hline
\end{tabular}

a Values obtained from $R B E_{\max }$

${ }^{\mathrm{b}}$ Data points at 16 and $21 \mathrm{keV} / \mathrm{\mu m}$

c Data points at 36, 45, 66 and $99 \mathrm{keV} / \mu \mathrm{m}$

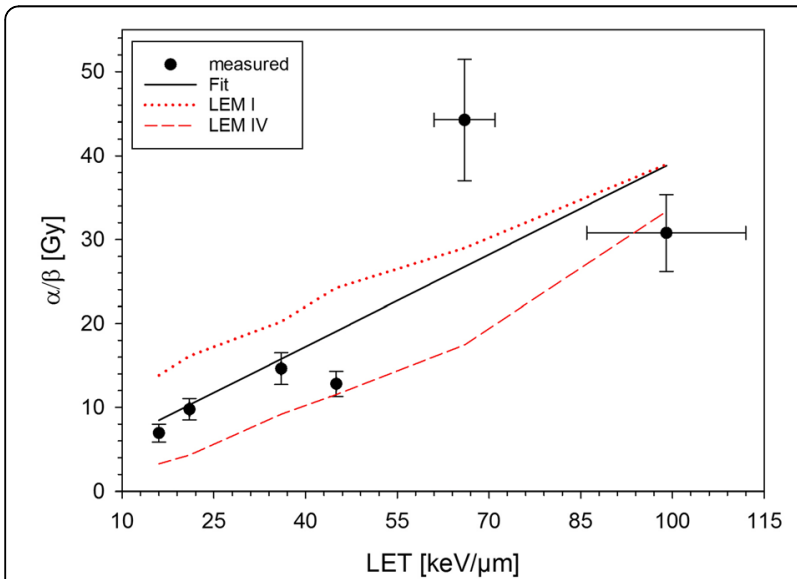

Fig. 6 a/ $\beta$-ratios at different depths within the SOBP interpolated by linear regression compared to predictions of LEM I and IV normal tissue. Since tumors are spatially heterogeneous, local changes of the radiation response and thus RBE are expected. As the underlying biological factors are generally not included in treatment planning, a non-uniform response within the tumor seems inevitable.

Normal tissues at risk, on the other hand, are typically located at the distal edge of the SOBP. It has been shown that optimizing the dose distribution with LEM I while assuming that LEM IV is actually correct, leads to extremely high doses in very small normal tissue volumes [20], which is in accordance with the experimental data presented here. The fact that the clinically observed incidence of normal tissue effects is nevertheless low, is thus likely attributable to a pronounced volume effect. To further tackle this aspect, a reliable volume effect model is missing. Clinically, this adds uncertainties to the expected treatment effectiveness, which may be handled by adjusting the prescribed dose while relying in the LET- and dose-dependence of the relative RBE-profile. 


\section{Conclusion}

With this study, a comprehensive in vivo data base for the RBE of carbon ions was established. This data was used to benchmark the LET- and dose-dependence of the RBE as predicted by LEM I and IV. While LEM IV agrees generally better in the SOBP, LEM I fits better in the entrance region. While this might support a model replacement in treatment planning, careful dosimetric analysis is required for the individual patient to evaluate potential clinical consequences.

\section{Appendix 1}

For each SOBP-depth of the spinal cord, the logistic dose-response model

$$
P(D)=\frac{e^{b_{0}+b_{1} D}}{1+e^{b_{0}+b_{1} D}}
$$

was adjusted using actuarial response rates. In equation 1a, $D$ is the total dose and $b_{0}$ and $b_{1}$ are the fit-parameters, from which $\mathrm{TD}_{50}$, can be calculated:

$$
T D_{50}=-\frac{b_{0}}{b_{1}} .
$$

\section{Appendix 2}

For each SOBP-depth, the parameter $\alpha / \beta$ of the linearquadratic (LQ) model [18] was estimated by adjusting the generalized logistic dose-response model

$$
\begin{aligned}
P(D) & =\frac{e^{b_{0}+b_{1} D+b_{2} D d}}{1+e^{b_{0}+b_{1} D+b_{2} D d}}=\frac{e^{b_{0}+b_{1} D\left(1+\frac{d}{b_{1} / b_{2}}\right)}}{1+e^{b_{0}+b_{1} D\left(1+\frac{d}{b_{1} / b_{2}}\right)}} \\
& =\frac{e^{b_{0}+b_{1} B E D}}{1+e^{b_{0}+b_{1} B E D}},
\end{aligned}
$$

to the actuarial response rates for 1, 2 and 6 fractions. In equation $2 \mathrm{a}, D$ is the total dose, $d$ the fractional dose and $b_{0}, b_{1}, b_{2}$ are fit-parameters, which allow calculating the $\alpha / \beta$-ratio [31] by

$$
\frac{\alpha}{\beta}=\frac{b_{1}}{b_{2}} .
$$

Using equation $2 \mathrm{~b}$, the expression $D\left(1+\frac{d}{b_{1} / b_{2}}\right)$ can be identified as the biologically effective dose, $B E D$ [18], and the right side of equation $2 \mathrm{a}$ thus describes the dose-response curve in terms of $B E D$ rather than absorbed dose. Accordingly, the BED at 50\% complication probability is given by

$$
B E D_{50}=-\frac{b_{0}}{b_{1}} \text {. }
$$

Within the LQ-model, the BED describes the extrapolated isoeffective dose in the limit of zero fractional dose.

\section{Abbreviations}

BED: Biologically equivalent dose; CL: Confidence limit; LEM: Local effect model; LET: Linear energy transfer; LQ-model: Linear-quadratic model; PMMA: Polymethyl-methacrylate; RBE: Relative biological effectiveness; SE: Standard error; SOBP: Spread-out Bragg-peak; TD: Tolerance dose; TRiP: Treatment planning for particles

\section{Acknowledgements}

We greatly acknowledge the excellent experimental conditions provided by the Heidelberg Ion-Beam Therapy Center (HIT) and the Center for preclinical research (ZPF) at the DKFZ. This work was supported by the German Research Foundation (DFG; KFO 214).

\section{Authors' contributions}

MS organized and performed the dose-response study as well as the animal monitoring during the study. She was involved in writing and revising the manuscript. CG contributed in performing the experiments and in revising the manuscript. PP initiated the project and was involved in the study design, data interpretation as well as in writing and revising the manuscript. SB supported the ion beam irradiations at HIT as well as dosimetry and treatment planning and was involved in revising the manuscript. RG performed the LEM calculations. MS performed the LEM calculations and contributed to data analysis and interpretation as well as to the revision of the manuscript. JD initiated the project and was involved in the study design as well as in the translational assessment of the data. CPK initiated the project and was involved in the study design. He performed the dosimetry, treatment planning, statistical analysis and was involved in data analysis and interpretation, writing and revising the manuscript. All authors read and approved the final manuscript.

\section{Funding}

This work was supported by the German Research Foundation (DFG; KFO 214).

\section{Availability of data and materials}

The datasets analyzed during the current study are available from the corresponding author on reasonable request.

Ethics approval and consent to participate

All experiments were approved by the governmental review committee on animal care (35-9185.81/G62-08, G117/13).

Consent for publication

Not applicable.

\section{Competing interests}

MS has a European Patent 10718875.7 with royalties paid by Siemens and RaySearch. MS, CG, PP, SB, RG, JD and CPK declare that they have no competing interests.

\section{Author details}

${ }^{1}$ Department of Medical Physics in Radiation Oncology, German Cancer Research Center (DKFZ), Heidelberg, Germany. ${ }^{2}$ Department of Radiation Oncology, University Hospital of Heidelberg, Heidelberg, Germany. ${ }^{3}$ National Center for Radiation Research in Oncology (NCRO), Heidelberg Institute for Radiation Oncology (HIRO), Heidelberg, Germany. ${ }^{4}$ Heidelberg lon-Beam Therapy Center (HIT), Heidelberg, Germany. ${ }^{5}$ Department of Biophysics, Helmholtz Center for Heavy Ion Research (GSI), Darmstadt, Germany. ${ }^{6} \mathrm{Clinical}$ Cooperation Unit Radiation Oncology, German Cancer Research Center (DKFZ), Heidelberg, Germany.

Received: 6 November 2019 Accepted: 6 December 2019

Published online: 03 January 2020

References

1. Suit H, DeLaney T, Goldberg S, Paganetti H, Clasie B, Gerweck L, et al. Proton vs carbon ion beams in the definitive radiation treatment of cancer patients. Radiother Oncol. 2010;95(1):3-22.

2. Karger CP, Peschke P. RBE and related modeling in carbon-ion therapy. Phys Med Biol. 2017;63(1):01TR2

3. Fossati $P$, Matsufuji N, Kamada T, Karger CP. Radiobiological issues in prospective carbon ion therapy trials. Med Phys. 2018;45(11):e1096-110. 
4. Castro JR, Linstadt DE, Bahary JP, Petti PL, Daftari I, Collier JM, et al. Experience in charged particle irradiation of tumors of the skull base: 19771992. Int J Radiat Oncol Biol Phys. 1994;29(4):647-55.

5. Kamada T, Tsujii H, Blakely EA, Debus J, De Neve W, Durante M, et al. Carbon ion radiotherapy in Japan: an assessment of 20 years of clinical experience. Lancet Oncol. 2015;16(2):e93-e100.

6. Kanai T, Furusawa Y, Fukutsu K, Itsukaichi H, Eguchi-Kasai K, Ohara H. Irradiation of mixed beam and design of spread-out Bragg peak for heavyion radiotherapy. Radiat Res. 1997;147(1):78-85.

7. Scholz M, Kellerer AM, Kraft-Weyrather W, Kraft G. Computation of cell survival in heavy ion beams for therapy. The model and its approximation. Radiat Environ Biophys. 1997;36(1):59-66.

8. Inaniwa T, Kanematsu N, Matsufuji N, Kanai T, Shirai T, Noda K, et al. Reformulation of a clinical-dose system for carbon-ion radiotherapy treatment planning at the National Institute of Radiological Sciences. Japan Phys Med Biol. 2015;60(8):3271-86.

9. Debus J, Scholz M, Haberer T, Peschke P, Jakel O, Karger CP, et al. Radiation tolerance of the rat spinal cord after single and split doses of photons and carbon ions. Radiat Res. 2003;160(5):536-42.

10. Karger CP, Peschke P, Sanchez-Brandelik R, Scholz M, Debus J. Radiation tolerance of the rat spinal cord after 6 and 18 fractions of photons and carbon ions: experimental results and clinical implications. Int J Radiat Oncol Biol Phys. 2006;66(5):1488-97.

11. van der Kogel AJ, Barendsen GW. Late effects of spinal cord irradiation with 300 kV X rays and 15 MeV neutrons. Br J Radiol. 1974;47(559):393-8.

12. Elsässer $T$, Weyrather WK, Friedrich $T$, Durante $M$, lancu $G$, Krämer $M$, et al. Quantification of the relative biological effectiveness for ion beam radiotherapy: direct experimental comparison of proton and carbon ion beams and a novel approach for treatment planning. Int J Radiat Oncol Biol Phys. 2010;78(4):1177-83.

13. Saager M, Glowa C, Peschke P, Brons S, Scholz M, Huber PE, et al. Carbon ion irradiation of the rat spinal cord: dependence of the relative biological effectiveness on linear energy transfer. Int J Radiat Oncol Biol Phys. 2014;90(1):63-70.

14. Saager M, Glowa C, Peschke P, Brons S, Grun R, Scholz M, et al. Split dose carbon ion irradiation of the rat spinal cord: dependence of the relative biological effectiveness on dose and linear energy transfer. Radiother Oncol. 2015;117(2):358-63.

15. Saager M, Glowa C, Peschke P, Brons S, Grun R, Scholz M, et al. The relative biological effectiveness of carbon ion irradiations of the rat spinal cord increases linearly with LET up to $99 \mathrm{keV} / \mu \mathrm{m}$. Acta Oncol. 2016;55(12):1512-5.

16. Krämer M, Jäkel $\mathrm{O}$, Haberer $\mathrm{T}$, Kraft G, Schardt D, Weber U. Treatment planning for heavy-ion radiotherapy: physical beam model and dose optimization. Phys Med Biol. 2000;45(11):3299-317.

17. Haberer T, Becher W, Schardt D, Kraft G. Magnetic scanning system for heavy ion therapy. Nucl Instrum Meth. 1993;A330:296-305.

18. Fowler JF. The linear-quadratic formula and progress in fractionated radiotherapy. Br J Radiol. 1989;62(740):679-94.

19. Friedrich T, Scholz U, Elsässer T, Durante M, Scholz M. Calculation of the biological effects of ion beams based on the microscopic spatial damage distribution pattern. Int J Radiat Biol. 2012;88(1-2):103-7.

20. Grün R, Friedrich $T$, Elsässer $T$, Krämer $M$, Zink K, Karger CP, et al. Impact of enhancements in the local effect model (LEM) on the predicted RBEweighted target dose distribution in carbon ion therapy. Phys Med Biol. 2012;57(22):7261-74

21. StatSoft I. STATISTICA für Windows [Software-System für Datenanalyse]. Version 6 wwwstatsoftcom; 2004.

22. Walker AM, Suit HD. Assessment of local tumor control using censored tumor response data. Int J Radiat Oncol Biol Phys. 1983;9(3):383-6.

23. Finney DJ. Statistical method in biological assay. 3rd ed. London: Charles Griffin; 1978. 1978

24. Bentzen SM. Preventing or reducing late side effects of radiation therapy: radiobiology meets molecular pathology. Nat Rev Cancer. 2006;6(9):702-13.

25. Coderre JA, Morris GM, Micca PL, Hopewell JW, Verhagen I, Kleiboer BJ, et al. Late effects of radiation on the central nervous system: role of vascular endothelial damage and glial stem cell survival. Radiat Res. 2006;166(3):495-503.

26. Leith JT, Lewinsky BS, Woodruff KH, Schilling WA, Lyman JT. Tolerance of the spinal cord of rats to irradiation with cyclotron-accelerated helium ions. Cancer. 1975;35(6):1692-700.

27. Leith JT, Woodruff KH, Lewinsky BS, Lyman JT, Tobias CA. Letter: tolerance of the spinal cord of rats to irradiation with neon ions. Int J Radiat Biol Relat Stud Phys Chem Med. 1975;28(4):393-8.
28. Bijl HP, van Luijk P, Coppes RP, Schippers JM, Konings AW, van der Kogel AJ. Dose-volume effects in the rat cervical spinal cord after proton irradiation. Int J Radiat Oncol Biol Phys. 2002;52(1):205-11.

29. Verhaegen F, Dubois L, Gianolini S, Hill MA, Karger CP, Lauber K, et al. ESTRO ACROP: technology for precision small animal radiotherapy research: optimal use and challenges. Radiother Oncol. 2018;126(3):471-8.

30. Weyrather WK, Ritter S, Scholz M, Kraft G. RBE for carbon track-segment irradiation in cell lines of differing repair capacity. Int J Radiat Biol. 1999; 75(11):1357-64.

31. Thames HD Jr, Rozell ME, Tucker SL, Ang KK, Fisher DR, Travis EL. Direct analysis of quantal radiation response data. Int J Radiat Biol Relat Stud Phys Chem Med. 1986;49(6):999-1009.

\section{Publisher's Note}

Springer Nature remains neutral with regard to jurisdictional claims in published maps and institutional affiliations.
Ready to submit your research? Choose BMC and benefit from:

- fast, convenient online submission

- thorough peer review by experienced researchers in your field

- rapid publication on acceptance

- support for research data, including large and complex data types

- gold Open Access which fosters wider collaboration and increased citations

- maximum visibility for your research: over $100 \mathrm{M}$ website views per year

At $\mathrm{BMC}$, research is always in progress.

Learn more biomedcentral.com/submissions 